\title{
STUDIA DOCTORALIA
}

PSYCHOLOGY AND EDUCATIONAL SCIENCE

\section{Aphasia - Conceptualization, symptomatology, and classification}

\author{
Cristian B. Belciu
}

University of Bucharest

\section{ARTICLE INFO}

Article history:

Received 04-October-2019

Accepted 28-October-2019

Available online 01-November-2019

This article should be cited as: Buică Belciu, C. (2019). Aphasia - Conceptualization, symptomatology, and classification. Studia Doctoralia. Psychology and Educational Science, 10(2), 114-124.

This is an open access article under the CC BY license (http://creativecommons.org/licenses/by/4.0/).

Corresponding author at: University of Bucharest, Department of Psychology, 90 Panduri Av, Bucharest, RO. Tel.: +40 (0)728 767055 .

E-mail address: cristianbuicabelciu@yahoo.com

\section{ABSTRACT}

The present theoretical study aims to make an incursion into the history of description, definition and conceptualization of aphasia. Old and modern opinions on the etiology and symptomatology of aphasia are presented. Also, the types of aphasia and their prognosis are described.

Keywords: aphasia, diagnosis, symptomatology

\section{INTRODUCTION}

Aphasia is focused on the study of language disorders caused by dysfunctions or lesions in the brain and adjacent nervous structures (Eling, 1994a), having interdisciplinary relationships with linguistics, psycho-neurology, and speech therapy. As subdivisions, we can notice the linguistic aphasiology, interested in the alterations of the verbal language at the level of structure and process, and the clinical aphasiology, dedicated to the practical problems regarding the evaluation and recovery of the patients with cerebral affections that have an impact on the verbal language.

Aphasia is defined generically as a disorder in the production and understanding of oral and written verbal language. It is caused by a unilateral brain injury in individuals with normal language development (Batiaanse \& Prins, 2014). Aphasia is a consequence of a central nervous system disorder (stroke, tumor, or brain injury). Symptoms specific to aphasia should not be confused with those encountered in hearing or visual impairments, dyslexia, 
dysarthria (central dyslexia), elective mutism, somatic disorders of the phonation organs or psychiatric disorders. If, for example, severe speech disorders occur in dysarthria due to disorders of the basal ganglia, brainstem, or cerebellum, the structure of articulated words is semantically and syntactically normal, and the patient can be understood by a careful listener. The ideatic flow is logically organized because the thought process is not affected. On the other hand, in the case of elective mutism, patients avoid communicating by any means, not just by speech. Moreover, in the case of brain disorders other than those responsible for the onset of aphasia, patients experience psychotic conditions during which major disorders of thinking and consciousness occur (Damasio, 1998).

\section{Historical synoptic \\ Precursors}

The link between acute brain trauma and speech loss must have been known since ancient times, at least from the time people used verbal language (Benton \& Anderson, 1988). Mentions of the absence of speech as a symptom of illness appear in the oldest medical documents (eg. in Edwin Smith surgical papyrus, a document dated as written between 300 and $220 \mathrm{BC}$ and which is a copy of an even older Egyptian manuscript) (Breasted, 1930), but without reference to brain activity (for the ancient Egyptians, the brain was an unimportant organ, unlike the heart) (Tesak \& Code, 2008). In Hippocrate's writings (especially in Coan prognosis) many descriptions of speech disorders appear, usually in the context of fatal conditions. In Romanians, Valerius Maximus (in the year 30 A.D.) describes the first case of traumatic alexia (Benton \& Joynt, 1960).

During the Renaissance, the Italian physician Antonio Guainerio mentioned two patients with aphasia: one could articulate only a few words, while the other's speech was almost unintelligible. Doctors such as Nicol Massa and Francisco Arceo reported improvements in speech in situations of skull fractures after removal of bone fragments (Benton \& Joynt, 1960). Also in Italy, Girolamo Mercuriale / Mercuriali (1530-1606) was the first to describe a case of alexia without agraphia, that of a typographer who, following an epileptic seizure, lost his ability to read, but not that of writing. The cause alleged by Mercuriale (like other doctors of the time, by the way) was a partial loss of memory (Meunier, 1911).

Johann Schenck von Grafenberg (1530-1598) described in a paper from 1585 (Observationes medicácia de capites humano) 16 cases of language disorders, most associated with brain trauma caused by open lesions in the skull. He noted that language disorders are not necessarily associated with paralysis. The Prussian physician Johannes Schmidt (1624-1690) described in 1676 the case of a patient who, following a stroke, could write after dictation, but who was unable to read what he had written. Gradually, he recovered, but remained alexical (Howard \& Hatfield, 1987). Peter Rommel (1643-1708) described in 1683 a patient with "aphonia" (aphasia) who had right hemiplegia and at the same time an inability to express himself in sentences and to repeat the simplest phrases. The automatic speech was kept, as evidenced by the recitation of prayers or versets from the Bible (Benton \& Joynt, 1960).

Giovanni Battista Morgagni (1682-1771) emphasized that anatomical lesions should be analyzed in terms of functional deficits. Noting that strokes were often accompanied by speech loss, he differentiated, in a 1762 paper, three types of problems: loss of voice, emissions of meaningless strings of speech, and speech impairments due to pathological changes of language (Benton \& Joynt, 1960).

In the eighteenth century detailed clinical descriptions of aphasic phenomena appeared. Olof von Dalin (1708-1763) mentioned in 1745 a patient who could only say "ja" ("yes"), but who could sing normally. The naturalist Carl von Linné (1707-1778) noted the case of an Uppsala professor who could no longer remember the names of those close to him (including his own) (Duchan, 2011). The German physician Johann Gesner (1738-1801) published in 1770 a monograph entitled "Amnesia of speech" in which he presented six case studies focusing on symptoms associated with aphasia (Luzzatti, 2002). In 1798, Alexander Crichton suggested that "speech amnesia" might be due to the inability of the patient to associate the ideational flow with the verbal language rather than a mental deficit (Benton \& Anderson, 1988).

\section{"Equipotentialists" vs. "localizationists"}

During the first decades of the nineteenth century, both theoretical-explanatory and clinical-therapeutic advances were made (Benton \& Anderson, 1988). Bouillaud (1825), Osborne (1833), Lordat (1843), Marcé (1856), Ogle (1867) had notable contributions (eg. Jacques Lordat referred to "alliance" when describing patients unable to speak; William Ogle used the term "agraphia" to designate spelling impairment).

Franz Joseph Gall (1758-1828), in his "organological" conception, considered that there are 37 fundamental faculties - intellectual, moral, and spiritual (such as mechanical ability, poetic talent, sense of ownership or propensity for crime) - for which certain regions of the brain are responsible. The particular shape of the skull was, in its conception, the result of the pressures exerted by certain areas of the brain on the bony tissue, which meant that correspondences could be established between certain personality traits and certain anatomical features of the skull. Gall reported that he became very early aware of the existence of relationships between mental functions and anatomical features of the skull, observing a schoolmate, very verbally gifted, who had well-developed protuberances 
in the frontal regions of the head (Heeschen, 1994). Johann Spurzheim, the assistant and later his partner, was the one who used the term "phrenology" to name Gall's anatomicalpsychological speculations, modifying them in his own way (O'Dell \& O'Dell, 1899).

On the other hand, Gall's observations of the wounded soldiers during the Prussian wars made him assign to the frontal lobes of the brain a special role in the use of language (although Gall himself was not interested in the subject). Jean-Baptiste Bouillaud (1796-1881), Gall's former student, took over from this the idea of localization, without giving credit to phrenological theories. Bouillaud classifies aphasic disorders into two categories: articulatory and amnestic. In a paper published in 1825 he distinguished between an ability to create words as signs of our ideas (internal language) and another to articulate those words (external language) (Benton \& Anderson, 1988). Beginning in 1825, Bouillaud has repeatedly argued that language disorders occur only after the frontal lobe injury, challenging his guild colleagues to present him a case of impairment of the frontal lobes that does not present speech disorder. His son-in-law, Ernest Auburtin (1825-1893), was able to find only cases where lesions of the frontal lobes were accompanied by language disorders (Caplan, 1998). Gabriel Andral (17971876), on the other hand, reported 37 cases of patients with lesions of the frontal lobes, of which only 21 had speech disorders during life; moreover, he observed 14 cases of aphasia in which, subsequently, he found lesions of the postrolandian areas, not at the level of the frontal lobes. Interestingly, however, of 11 cases of unilateral brain injury, five had lesions in the left hemisphere (three were aphasic) and six in the right hemisphere (none being aphasic). Andral's intention to show that it is not necessary to affect the frontal lobes in the case of aphasia seems to have made him ignore the correlation between the left cerebral hemisphere and aphasia (Benton \& Anderson, 1988). Another "holist" (as opposed to "localizationists"), Pierre Flourens (1794-1867) concluded, following coarse ablations of the brain, that the resulting behavioral disorders were similar, regardless of the affected brain area. Moreover, stimuli of the cerebral cortex did not produce any reaction, which led him to the idea that psychic functions were homogeneously distributed at the brain level ("cortical equipotentiality", in modern terminology) (Finger, 1994).

In this context, Paul Broca (1824-1880), an admirer of Gall's theories (Eling, 1994b), invited Auburtin to examine a patient at Bicêtre Hospital. He, by the name of Leborgne, was known as "Tan" in the hospital, because the only syllable he could pronounce was "tan". He understood what he was being told and knew how to make his needs known. Broca was aware of the case when the patient suffered paralysis of the right arm, followed by that of the right leg. A few days after examination, Leborgne died of septicemia. Broca examined his brain as soon as the autopsy was performed and found the presence of a cyst at the base of the third inferior frontal circumference. He also noted that the cerebral tissue around the cyst was more fragile than it should have been, a phenomenon also found in the region above the sylvian fissure (parietal operculum). Making correlations between the clinical symptoms and the anatomical changes, Broca attributed the language deficit to the lesion from the base of the mentioned frontal gyrus, the appearance of the face and arm as the extension of the lesion to the adjacent motor strip, and the paralysis of the leg as to the wider dissemination of the lesion in the posterior area. It should be noted that Leborgne could not write, and the understanding was deficitary at the time of his examination. In 1863, Broca described eight cases of "aphemia", all presenting at the autopsy with lesions in the left frontal lobe. During the same year, Jules Parrot made public the case of a patient who had a right frontal lobe lesion without manifesting any language disorder. In an 1865 article (Du siège de la faculté du langage articulé), Broca stated that "we speak with the left hemisphere" ("Nous parlons avec l'Hémisphère gauche"). To make things not at all simple, the discovery claimed by Broca in 1861 had been made 25 years before by the French physician Marc Dax (1770-1837), but his death prevented the propagation of the novelty in the scientific world of the time (Joynt \& Benton, 1964). Returning to Broca, it should be emphasized the definition that he gives to "the faculty of articulated speech", that of the function of coordinating the individual movements in speech (taken from Bouillaud), with the addition that this "faculty" should be considered a kind of not memory of words, but of the procedures to be followed to articulate words (Eling, 1994b). Interestingly, Broca and Charcot studied a case of aphasia which, at autopsy, showed an extended lesion in the posterior area of the brain, not at the level of the third left frontal circumference (possibly a sensory aphasia). In addition to these aspects, Broca found a variable correlation between the severity of brain damage and that of the resulting aphasia, which led him to the idea that the right hemisphere would have a certain role in verbaloral production (Eling, 1994b).

The French neurologist Armand Trousseau (1801-1867) coined the current term of "aphasia" in 1865 (Hécaen \& Dubois, 1969), ending the terminological rivalry between "alalia", "aphemia", and "aphasia". This fact was the consequence of a famous debate at the time (1864), between him and Paul Broca, in which he fought against the precise location of "aphemia" on the basis of cases of aphasia with different locations (Keyser, 1994). Trousseau (1864) drew attention to the fact that the term "aphasia" (meaning "without language" in Greek) was more appropriate than that of "aphemia" ("without speech"), a distinction that is still preserved today.

In the context of this dispute, Carl Wernicke (1848-1905), assistant in the laboratory of Theodor Meynert (1833-1892), 
famous neuropathologist in Vienna, took on his conception regarding the division between the anterior motor cortex and the posterior sensory cortex, the two entities being interconnected by numerous projection fibers, association fibers and commissural fibers (Whitaker \& Etlinger, 1993). In his doctoral thesis of 1874, Wernicke described cases of sensory aphasia due to lesions in the left posterior superior temporal gyrus (Filley, 2011). He considers that the loss of "motor memories" (motor representations) determines the inability to mobilize the structures involved in verbal-oral articulation. Sometime earlier, Carl Maria Finkelnburg (1870) had observed in the aphasic patients deficiencies of understanding and expression of the nonverbal signs (the case of an aphasic musician who could no longer decipher the scores or that of a seller who confused the values of various currencies). Finkelnburg stated that it is a case of asymmetry rather than an aphasia. On the other hand, he rejects the location of the speech center in the left hemisphere in favour of the right (Goldenberg, 2013).

In the United Kingdom, John Hughlings Jackson (18351911) was skeptical about the precise location of the language function. In an 1874 article, he noted that locating the lesion that destroys speech and locating speech are two different things. A disciple of the philosopher Herbert Spencer, Hughlings Jackson became little noted abroad, on the one hand because of the Spencerian phraseology used, and on the other, because he generally published in magazines with limited circulation (Code, 2012). His work was later popularized by Henry Head (1915), and today it is recognized as an important precursor of aphasiology. Essential in his conception is the distinction between words and sentences. Hughlings Jackson argued that speech consists of words that relate to each other in a particular way (sentence). A sentence denotes a relationship between certain symbols or "images" (representations) of things, so this is the unity of speech. Therefore, the meaning of a sentence goes beyond the simple summation of the meanings of the words that make it up. He considered that the nerve structures responsible for speech were located in the left hemisphere, and those that achieved the understanding of the words in the right hemisphere (Schulte, 1994).

The Swiss Jules J. Déjérine (1849-1917), a student of Charcot, created his own aphasia classification system; his main contribution is to locate the alexia and the agraphia at the level of the left angular gyrus. Déjérine (1914) distinguished four types of language disorders: aphasia, dysarthria (anarthria), mutism, and stuttering, of which only the first two were caused by brain damage. Déjérine defined aphasia as "loss of memory of the signs with which the civilized man exchanges ideas with his peers" (Renier, 1994). His opponent, Pierre Marie (1853-1940) argued that there is only one type of aphasic syndrome, the one described by Wernicke, and Broca's aphasia consisted only of the additional presence of anarthria (Broca's aphasia) (Lebrun, 1994). In 1917, after examining a large number of soldiers with aphasic trauma, Marie introduced three clinical variants - temporal aphasia (due to supramarginal gyrus injury), posterior aphasia, and limited aphasic syndrome without providing detailed explanations. Albert Pitres (18481928 ) is particularly noted for his research on amnesty aphasia (variety considered by him to be characterized by forgetting names) (Benton, 1988).

\section{Modern conceptualization of aphasia}

The antebellic period marks the significant contribution of linguists to the development of aphasiology, which weighs the medical content since then. The contributions were Arnold Pick (1851-1924) regarding the study of agramatism (considered by him as the essential aphasic symptom), Karl Kleist (1878-1960), who distinguished between agramatism and paragramatism (the latter referring to the modality of erroneously order the words in sentences and phrases, with amalgamations and contaminations, confusing developments, incompleteness), Roman Jakobson (18961980) with the regression hypothesis (according to which the dissolution of the phonetic system in aphasia represents the mirror image of its development in childhood).

As the defeat of France in 1871 led to the primacy of German aphasiology, the end of World War II meant the assertion of Soviet and American aphasiology respectively. New developments in the conceptualization of aphasia, but also modern therapeutic approaches, appeared after World War II. The large number of soldiers with brain injuries gave Aleksandr R. Luria (1902-1977) the necessary guidance to approach a new perspective on the organization of cognition and language (Luria, 1962), as well as the reclassification of forms of aphasia (Luria, 1970). Luria described dynamic (or frontal) aphasia, caused by a lesion of the left anterior prefrontal lobe, having as characteristic symptoms an apparent unwillingness of the patient to speak, as well as a disturbance of the internal language. Later, it was renamed transcortical motor aphasia.

Luria (1964) presented two distinct forms of motor aphasia: the efferent (kinetic) motor aphasia, caused by a lesion of the inferior frontal areas of the left premotor area, respectively the related motor (kinesthetic) aphasia generated by lesions of the inferior region of the left postcentral parietal cortex. The first form corresponded to the Broca-type motor aphasia; the second will be renamed aphasia of transmision. Sensory aphasia, in Luria's classification, was caused by damage to the superior and posterior regions of the temporal lobe, corresponding to the Wernicke-type sensory aphasia. Acoustic-amnestic aphasia, a consequence of a lesion in the middle gyrus of the temporal lobe, leads to incapacitation of verbal memory (reclassified as transcortical sensory aphasia). Semantic aphasia, produced by lesions of the parieto-temporo- 
occipital region in the posterior part of the left cerebral hemisphere, has the effect of losing the meaning of verbal constructions, although patients understand the meaning of individual words. This type of aphasia corresponds to the anomalous aphasia, in the classification proposed later by Benson and Geschwind (1971).

Norman Geschwind (1926-1984), Boston neurologist, restored interest in the cortical localization of language, a scientific current known as neoconnectionism, which dominated the world of aphasiology from 1960 to 1980. Geschwind was influenced by the work of Wernicke and Déjérine and has the merit to have shown that the beginning literature in the field contains a lot of well documented cases. He considers cortico-cortical connections to be an extremely important mechanism. He applied the concept of "disconnection syndrome" in explaining apraxia (Kean, 1994).

Geschwind ends the era of postmortem studies and observational inferences, because technological advancement will make it possible, in more and more depth, to explore brain activity in situ. Electroencephalography, radioactive isotope scanning (1960), computerized tomography (1973), magnetic resonance imaging (1980), functional magnetic resonance imaging, PET (positron emission tomography) (1990) created incomparably more productive research opportunities than classical ones. The development of neuroimaging techniques takes place in three directions: structural, functional, and analysis techniques.

\section{Definition, differentiation, etiology, and frequency}

Aphasia is a language disorder with a brain lesion origin that is manifested by deficiencies in one or more communication modes: auditory comprehension, verbal-oral expression, writing and reading, respectively functional communication (Damasio, 1998; Davis, 2014).

Defining aphasia as a language disorder should not be confused with articulatory disorders (dyslalia and dysarthria). Dysarthria is a motor disorder of speech, while apraxia of speech is a disorder of motor programming and articulatory monitoring. In dysarthria, although the form of verbal-oral communication is affected, the content remains intact. This fact can be ascertained either by listening carefully to the patient's speech with dysarthria, or by interacting with him by other means: mimicry, gesturing, writing. Communication disorders that occur in Alzheimer's and other dementias are not confined to the definition of aphasia, as there is no unilateral brain injury, and these are progressively worsening. Aphasia must be differentiated from the conditions of language development in children, in particular alalia. There is only one exception here: the (acquired) child's aphasia, resulting from a brain trauma or stroke that occurred at a critical age for normal language development.
Primary progressive aphasia is a progressive form of dementia, characterized by continuous degradation of linguistic functioning, but with the preservation of cognitive and mental functions and personality traits. It has been described by Marsel Mesulam (1982) as a distinct syndrome. It is not part of the aphasia classification discussed before.

Aphasia must be differentiated from psychopathological or psychiatric disorders. In the case of mutism, these patients do not communicate in any way and do not show that they understand what they are told. Some of them may have lesions other than those affected by aphasia, such as in the cingulate gyrus or additional motor area, or the neurotransmitter system may be affected. Aphasia is not confused with voice disorders, not even those of a psychiatric nature (hysterical aphonia) (Damasio, 1998).

Aphasia occurs in the case of a lesion in the left cerebral hemisphere, affecting the cortex, the white matter or both. Very rarely, aphasia is established after the single right hemisphere injury in persons with language functions located here (Dewarrat et al., 2009). Aphasia can result from lesions of deep subcortical structures in the left cerebral hemisphere, including the thalamus, internal and external capsules, basal ganglia (especially the caudate nucleus), hence the name of subcortical aphasia (Boissezon et al., 2005).

The most common cause is stroke (about $85 \%$ of cases). There are two possible ways: either by infarction (partial or total blockage of the arteries by thrombosis) or by hemorrhage (which, on the one hand, decreases the supply of oxygen and nutrients to the brain cells and, on the other, through overflow into a closed space in the brain, increases intracranial pressure on other cortical structures). The second important cause is acute brain trauma. There is an essential difference between localized and reduced trauma caused by gunshot or shrapnel and the extended one resulting from car or workplace accidents or injuries. It can be said that modern wars, especially the world wars (by the large number of wounded soldiers), have served to develop Soviet, British, and American aphasiology. The third cause, according to frequency, is brain tumors. These, regardless of their benign or malignant character, grow, change the structure of the election zone and exert pressure on the surrounding areas. Finally, the fourth most important cause is the infectious one (meningitis, encephalitis) (Batiaanse \& Prins, 2014). In rare cases, the herpes virus can affect the frontal and temporal lobes, subcortical structures, hippocampal tissue causing herpesviral encephalitis, which, among other manifestations, also presents aphasia (Naudé \& Pretorius, 2010).

There is no precise statistics of the incidence (the number of new cases registered in a year) or the prevalence (the number of cases existing in a given time interval) of the aphasia. Estimates range from 0.3 to $0.5 \%$ of the general 
population, with the percentages being significantly higher in the sample of elderly people: $43 \%$ of people over 85 are affected by aphasia (Engelter et al., 2006). There were no differences in the incidence between men and women, although there are studies that argue that Broca's aphasia occurs more frequently in men and Wernicke's in women (Hier et al., 1994).

\section{General symptomatic picture}

1. with the exception of the first hours or days after the onset of the condition, the patient with aphasia may speak some sounds and words, in certain situations he may have an abundant verbal flow, without his verbal production complying with the grammatical rules. Errors include omissions of words such as conjunctions and prepositions, incorrect choice of words, distortions of the relationship between words in the sentence. Even in the absence of speech phase, the patient usually tries to communicate through mimicogesticulation.

2. the patient with aphasia usually has difficulty understanding a purely verbal command. Misunderstandings range from complete inability to grasp the meaning of the simplest questions to slight defects that are noted if the patient is trying to communicate complex sentences.

3. the patient with aphasia is aware of himself and the environment, he tries to communicate with the medical staff and with those around him. In the first hours after the onset of the condition, the aphasic patient may appear absent or uninterested in communication; also, chronic patients might be diagnosed with depression.

Critical in the verbal formulation is the ability to select from the lexicon (vocabulary) the precise word that designates the idea that is required to be expressed. When finding the right word fails, the result is either the omission of the search term (marked by the extension of the vowel "ă") or the replacement with another word, wrongly chosen and unintentional. Substitution is called a paraphrase. If it refers to the word, we mean verbal or global paraphrase; if the substitution is part of the same semantic area ("chair" instead of "table"), it is called semantic paraphrase. Finally, if the speech abounds with verbal paraphrases in a sentence, then jargonophase appears. When a single phoneme is replaced or added, the symptom is referred to as a phonemic or literal paraphrase. The excess of phonemic paraphrases produces an unintelligible word, and the abundance of "neologisms" is responsible for the emergence of neologistic jargon.

Paraphrases are a typical symptom in aphasia. They appear in spontaneous or dialogical speech, but also in the repetition of sentences spoken or read aloud, in tasks that require name and in writing, but are usually missing in automatic speech (counting from 1 to 10, the calendar months in suite, exclamations). The pacient's own lexical organization causes the paraphrases not to affect all the words, but they affect more certain lexical categories than others.

The fluency of speech reflects its normal flow in terms of the rate of word production in the unit of time (minute), length of the sentence, melodic contour (timbre), intonation, stress, in other words, the ease of performing the verbal-oral act. Hence also the division into: fluent aphasia (in which verbal production may be even more abundant than normal) and non-fluent aphasia (low production rate speech, short sentences, absent melodicity, difficult articulation, frequent pauses).

It must be said that the difficulties of articulation are not of a motor nature (as in dysarthria) or of motor planning (as in verbal dyspraxia), but of the composition of words and sentences. In fact, many patients with non-fluent aphasia keep their articulatory skills intact. Even those with severe forms are capable of producing fully articulated, automated verbal sequences.

The inability to repeat words or sentences is another hallmark of aphasia. The ability to repeat may be completely abolished or may be influenced by phonemic paraphrases or omissions of sounds and words. The symptom is typical in transmision aphasia, perhaps because other pronounced deficiencies are missing. The localization of this ability is in the perisylvian region of the left cerebral hemisphere. Repetition deficiencies are absent in the transcortical aphasia, as well as in the anomalous aphasia, whose correlated lesions are located outside the perisylvian ring. On the contrary, patients with transcortical aphasia may even exagerate, immediately repeating the words of the examiner, often without knowing what they are saying (a disorder called ecolalia).

Hearing comprehension (the words heard) can be affected to a different extent. While some patients are able to hold a conversation at the colloquial level, offering the expected verbal replies or showing (through indicative gestures, nodding movements, facial expressions) that they understand what is being discussed, however, when tested, they fail on many items, especially when are asked specific questions and when the linguistic structure is complex. Others show poor understanding not only in tests but also in less demanding conversational situations.

Another characteristic symptom in aphasia is agramatism. It refers to the difficulty of generating syntactic frames in which lexical selections can be placed (propositional structures). It also envisages the faulty use of grammatical morphemes with the role of prefixes, affixes, suffixes (free and inflectional, that is, those marking grammatical time, number, person etc.). Agrammatism is evident in the Broca type aphasia, but, to some extent, it appears in other types of aphasia.

Reading comprehension can be affected as much as hearing comprehension, although the two deficiencies are 
not always associated. If patients with hearing impairment usually present some lexical problems, dyslexia may manifest in pure form, without affecting hearing comprehension or writing. In general, most cases of aphasia impair hearing comprehension, reading and writing, but with varying degrees of severity.

An important aspect in differential diagnosis is comorbidity with apraxia. From this perspective, the manifestation of apraxia becomes a signal (marker) for the existence of aphasia. Aphasia is a separate nosological entity, which must be addressed separately (Damasio, 1998).

\section{Classification of types of aphasia}

As we have seen in the historical trip, there have been many terminological, taxonomic, and semiological disputes over the last 200 years. Typically, classical types of aphasia are two: expressive aphasia (Broca type) and receptive aphasia (Wernicke type).

The National Association of Aphasia in the U.S. recognizes the following varieties, according to the neoconnectionist model proposed by Geschwind (1965) and his disciples (Goodglass \& Kaplan, 1972):

1. Non-fluent aphasia (Broca), in which verbal production is severely limited, up to a maximum of four words. Access to vocabulary is limited. The articulation of phonemes is laborious and clumsy (hence the quality of "non-fluent"). Some people have more difficulties using verbs than nouns. The patient can understand the speech quite well, especially when the grammatical structure is simple. He may read, but expression in writing is limited. The melodic contour is absent. The general impression is of speaking in "telegraphic style" due to both the elimination of morphemes and the disturbance of the correct grammatical order of the words in the sentence. Aphemia is an articulatory disorder caused by small lesions located below the motor cortexes or in the vicinity of the basal ganglia and which can be confounded with Broca's motor aphasia. The lesions affect the frontal operculum (areas 44 and 45), but also the motor and premotor regions located immediately behind and above, extending to the white subcortical substance and basal ganglia and even to the island (Damasio, 1998).

2. Mixed non-fluent aphasia, encountered in patients with difficult, laconic speech, similar to that of Broca's aphasia. Speech comprehension is low, similar to those affected by Wernicke's aphasia. Writing-reading skills do not exceed the elementary level.

3. Fluent aphasia (Wernicke) is noticeable by the lack of understanding of the meaning of the spoken words, while the connected speech is not affected too much. Patients with this type of aphasia can spell many words, often used in grammatically correct sentences, normal in rate and prose. Frequently, what they say doesn't make much sense or introduce irrelevant or non-existent words from time to time.
They may be unable to realize that they are using the wrong or invented words and often are not fully aware that what they say makes no sense. Patients with this type of aphasia manifest deep understanding deficits, even with regard to isolated words or simple sentences. Both reading and writing are affected. If right hemiplegia or hemiparesis facilitates the diagnosis of Broca's aphasia, in Wernicke's aphasia right hemiparesis is rare or temporary. Visual field disorders are not a rule. For the non-specialist, the sensory aphasia takes on the appearance of a confusing state with psychiatric significance. Patients with this type of aphasia have a higher tolerance for frustration than those with motor aphasia, who burst into tears and abruptly refuse to cooperate in the event of failure. On the other hand, there is a tendency for paranoid ideation in patients with sensory aphasia who may develop into a major paranoid syndrome with homicidal consequences. Critical lesions are present in the posterior region of the left superior temporal gyrus. The lesions frequently extend to the second temporal gyrus as well as the neighboring parietal region (the inferior segment of the supramarginal and angular gyrus) (Damasio, 1998).

4. Anomic aphasia (one of the mild forms of aphasia) is typical for people who denote a constant inability to find the right words for what they just want to say, especially nouns and verbs. Their speech is fluent and grammatically correct, but parasitized by all sorts of vaguenesses (such as the word "thing"). They often seem to have the word "on the tip of the tongue", hence the inclusion in the speech of expressions that indicate frustration. This feature is diagnostic for this type of aphasia. Responsible lesions are located outside the perisylvian circle, especially in the anterior and lower left temporal regions.

5. Global aphasia (the most severe form) is specific to patients who can articulate a few recognizable words and who understand little or no spoken language. These patients are unable to write or read. It is caused by extensive lesions in several areas involved in language processing, including the classical ones (Broca and Wernicke). Global aphasia may be transient, occurring immediately after stroke or trauma, and diminishing in the following months, depending on the degree of cortical impairment. Hemiplegia accompanies most cases. The typical lesion is located in the left perisylvian region, affecting all areas involved in aphasia $(44,45,41,42,22,40$, portions of 39 and 37). Motor and somatosensory areas $4,3,1$, and 2 are also affected. Moreover, the white subcortical substance is damaged, as are parts of the lenticular and caudate nuclei (Damasio, 1998).

6. Progressive primary aphasia (PPA) is a rare neurological syndrome characterized by slow and continuous slowing and degradation of language skills, while other mental functions are preserved. Unlike ordinary types of aphasia, progressive primary aphasia is, in fact, a degenerative brain disorder located in the areas dedicated 
to speech and language. Minor speech disorder at onset, this progresses to total inability to speak, in the most severe cases. The symptomatological pattern differs from patient to patient. In some it takes the form of a fluent aphasia, in others it manifests as a non-fluent aphasia. In some cases there is a variety in which there is an impairment in finding words, a progressive deterioration of the names and the understanding of the speech, at the same time with the relative retention of the ability to articulate. In contrast to Alzheimer's disease, the progressive primary aphasia preserves the skills of personal autonomy, personal interests, and professional skills that do not involve the use of language. In contrast to the classical forms of acquired aphasia, in which the remission of the hematoma and the functional compensation diminish the symptoms, in this case the manifestations are aggravated irreversibly. It is an incurable condition.

7. Other forms of aphasia refers to combinations that are not in the classical typology (NAA, 2016).

In fact, the clinical forms are much more diverse, due to the variability of the extent and depth of the lesions, which makes the precise taxonomic classification difficult (Manasco, 2016).

Transmision aphasia is characterized by fluent speech, less abundant than in Wernicke's aphasia. Minor impairments usually occur in the area of hearing comprehension, although understanding of the usual conversation remains intact. Impairments related to repetition of words and sentences are typical. Patients often repeat words with phonemic paraphrases, but they often express verbal paraphrases or omit whole words. Understanding defective repeated sentences is good. Also, patients understand the read sentences with many paraphrases. Certain motor symptoms may be present (paresis of the right half of the face and upper right extremity), but recovery is good. It is associated with lesions of the left perisylvian region, affecting the primary auditory cortex (areas 41 and 42), part of the surrounding cortical association area (area 22) and, to a varying extent, lesions of the island and the white matter surrounding subcorticals, as with lesions of the supramarginal gyrus (area 40) (Damasio, 1998).

Transcortical sensory aphasia (TSA) is characterized by fluent speech, with global paraphrases rather than phonemes, and severe hearing loss. However, the capacity for repetition is preserved (with ecological manifestations, occasionally), which is the distinguishing feature in relation to Wernicke's aphasia. The posterior segment of area 22 of the superior temporal gyrus (Wernicke area) is never completely injured. The same can be observed in primary auditory cortical areas. However, lesions are present in the posterior sector of the middle temporal gyrus (area 37), in the angular gyrus (area 39) or in the white subcortical substance (Damasio, 1998).
Transcortical motor aphasia (TMA) is characterized by the ability of complete repetition (sometimes echolalia). Speech is not fluent, but is affected by phonemic and global paraphrases, perseverance, and loss of connecting words. Hearing comprehension is poor in testing, but patients can manage a simple conversation. The appearance of speech is similar to that of the Broca type aphasia (phonetic, lexical, syntactic errors are numerous). The lesions are invariably placed outside the Broca area, either anterior or superior to it, or deep in the left frontal cortex or white matter, near the anterior horn of the left lateral ventricle. Although akinetic mutism does not fall into the category of aphasia, on the tomographic examination lesions are observed in the frontal lobe, affecting the additional motor area (medial portion of area 6), its connections and the anterior cingulate gyrus (area 24). However, the lesions do not extend to the aphasia-specific frontal regions. Mutism is often confounded with motor transcortical aphasia, which is why it is mentioned here (Damasio, 1998).

Alexia with agraphia (extremely rare). Patients often have signs of Wernicke's aphasia or transcortical sensory aphasia. In the absence of aphasia, however, it shows symptoms of dysfunction of the parietal lobe. The diagnosis of agraphia-alexia is only made if the writing-reading disorders prevail in relation to the aphasic or parietal symptoms. The fact that parietal dysfunction syndrome may be associated with intact or impaired repetition ability, as well as with other symptoms, suggests that a consistent segment of cortical and subcortical structures in the parietal and temporal lobes is involved in the complex process of writing and reading.

Pure alexia (no agraphia). Patients suffering from this disorder cannot read, while being able to write, spontaneously or after dictation. Many of them manage to copy texts, although they do this with difficulty. Speech, hearing comprehension, and repetition ability remain intact. Oral spelling of words (or, conversely, word construction on letters) is normal. Tactile reading is normal. Because the patient can visually identify only isolated letters, he reads aloud each letter of a word, and then reconstructs the word in his mind. In most cases, a visual function impairment is observed, although there are no problems with writing or speaking. This deficit can be homonymous right hemianopia (visual field to the right of the median line is blind) or right hemiacromatopsy (loss of color perception without blindness in the right hemicampus). Most patients also have chromatic abnormality, color naming disorder despite normal chromatic perception. Some have optic ataxia, that is, a disorder of oculomanual coordination. The syndrome was first described by Déjérine in 1892 and rediscovered by Geschwind (1965) following extensive and in-depth readings by classical authors.

Topologically, the lesion extends from the deep occipital cortex into the white matter, reaching the left lateral 
ventricle. It involves the primary visual cortex (area 17) and parts of the cortices of the associative visual areas (18 and 19), extends into the occipitotemporal medial junction, affecting the medial area 37 and the posterior sector of the hippocampal gyrus (Damasio, 1998).

Pure verbal deafness. Patients have a profound deficit of hearing comprehension and a total loss of repetition ability. However, speech is normal, fluent, without paraphrases to a large extent. Both pure alexia and pure verbal deafness do not meet the criteria for the category of aphasia, because the linguistic formulation itself is not affected. Both conditions reflect the inability of verbal information to reach structures capable of translating them into meaningful content. On the other hand, they resemble aphasia from the point of view of the communication deficiency they produce. In addition, the comparative study allowed a better understanding of the mechanisms underlying the production of aphasia.

Atypical aphasia. For various reasons, there are varieties of aphasia that cannot be included in the typology described above. The non-standard disposition of cerebral dominance can be expressed in a linguistic dominance of the right cerebral hemisphere in both the left and the right. There may also be linguistic "ambidominance" on the left. Injuries to the deep structures (thalamus or basal ganglia) of the gray matter, with interest of the white matter (from the anterior limb of the internal capsule) are responsible for the so-called "subcortical aphasia". Nonhemorrhagic infarction affecting the left head of the caudate nucleus and the anterior limb of the internal capsule may give rise to aphasia; similarly, left thalamus injury following hemorrhagic or nonhemorrhagic infarction (Damasio, 1998).

\section{Recovery and prognosis}

Until recently it was considered that the cells in the brain do not regenerate and that, therefore, the lesions in the brain

\section{REFERENCES}

Alajouanine, T., Ombredane, A., Durand, A. (1939). Le syndrome de désintégration phonétique dans la l'aphasie. Paris: Masson.

Bastiaanse, R., Prins, R. S. (2014). Aphasia. In L. Cummings (coord.), The Cambridge handbook of communication disorders (pp. 224-246). Cambridge: Cambridge University Press.

Benson, D. F., Geschwind, N. (1971). Aphasia and related cortical disturbances. In A. Baker şi L. H. Baker (coord.), Clinical neurology (pp. 112-140). New York: Harper \& Row. Benton, A. L. (1988). Pitres and amnesic aphasia. Aphasiology, 2, 209-214.

Benton, A. L., Anderson, S. W. (1998). Aphasia: Historical perspectives. In M. T. Sarno (coord.), Acquired aphasia (ed. a treia, pp. 1-24). San Diego, CA: Academic Press. are irreversible. Some cells that have stopped functioning due to lack of oxygen can regenerate. This phenomenon provides a tissue explanation for the improvements that occur in aphasia in the first months after the traumatic event. The cerebral edema remits in about two to three months (after the acute stage), decreasing the pressure exerted on the cerebral tissue, which allows the surviving cells to resume their functions. Also, some connections between cells can regenerate during the first weeks or months (Carmichael, 2006). Thus, in most patients, an episode of spontaneous recovery of cognitive and physical functions occurs; after this period, the aphasia remains permanent, although improvements in language and communication are still possible.

There are four major factors that influence recovery and prognosis in aphasia:

1. Degree of severity: patients with severe aphasia, usually as a result of an extended lesion, have a reserved prognosis in relation to patients with mild aphasia, especially after the period of spontaneous recovery;

2. Age: the prognosis is better, the younger the patient;

3. Cause: Traumatic aphasia usually has a better prognosis than ischemic aphasia. In this case, the age gap also matters, with stroke being much more frequent in the elderly;

4. Manual laterality: left-handed and ambidextrous people generally have better chances of spontaneous recovery than right-handed (a phenomenon explained by the bilateral organization of language in the former).

Aphasia therapy aims to influence the recovery process, but there is no consensus among specialists on the most effective method. Psychological (motivation) or biological (physical health) factors can have a positive effect, which has not yet been demonstrated (Batiaanse \& Prins, 2014).

Benton, A. L., Joynt, R. L. (1960). Early descriptions of aphasia. Archives of Neurology, 3(2), 205-222.

Berker, E. A., Berker, A. H., Smith, A. (1986). Translation of Broca's 1865 report: Localization of speech in the third left frontal convolution. Archives of Neurology, 43(10), 10651072.

Boissezon, X. de, Démonet, J.-F., Puel, M., Marie, N., Raboyeau, G., Albucher, J.-F., et al. (2005). Subcortical aphasia: A longitudinal PET study. Stroke, 36, 1467-1473.

Bouillaud, J. B. (1865). Recherches cliniques propres a démontrer que la perte de la parole correspond à la lésion des lobules antérieurs du cerveau et à confirmer l'opinion de M. Gall sur le siège de l'organe du langage articulé. Archives Générales de Médicine, 3, 25-45. 
Breasted, J. H. (1930). The Edwin Smith surgical papyrus (2 vols.). Chicago: University of Chicago Press.

Broca, P. (1863). Localisation des fonctions cérébrales: siège du langage articulé. Bulletin de la Société d'Anthropologie, 4, 200-203.

Broca, P. (1865). Du siège de la faculté du langage articulé. Bulletin de la Société d'Anthropologie, 6, 337-393.

Caplan, D. (1987/1998). Neurolinguistics and linguistic aphasiology: An introduction. Cambridge: Cambridge University Press.

Carmichael, C. T. (2006). Cellular and molecular mechanisms of neural repair after stroke: Making waves. Annals of Neurology, 59(5), 735-742.

Code, C. (2012). Significant landmarks in the history of aphasia and its therapy. In I. Papathanasiou, P. Coppens şi C. Potagas (coord.), Aphasia and related neurogenic communication disorders. Burlington, MA: Jones \& Bartlett. Crichton, A. (1798). An inquiry into the nature and origin of mental derangement. Londra: T. Cadell, Jr. \& W. Davies.

Damasio, A. R. (1998). Signs of aphasia. In M. T. Sarno (coord.), Acquired aphasia (ed. a treia, pp. 25-42). San Diego, CA: Academic Press.

Damasio, H. (1998). Neuroanatomical correlates of the aphasias. In M. T. Sarno (coord.), Acquired aphasia (ed. a treia, pp. 43-70). San Diego, CA: Academic Press.

Davis, G. A. (2014). Aphasia and related cognitivecommunicative disorders. Upper Saddle River, NJ: Pearson. Dax, M. (1865). Lésions de la moitié gauche de l'encéphale coincidant avec l'oubli des signes de la pensée: Lu au Congrès méridional tenu à Montpellier en 1836. Gazette hebdomadaire de médicine et chirurgie, 2, 259-260

Déjérine, J. (1892). Des différentes variétés de cécité verbale. Memoires de la Société de Biologie, 9, 61-90.

Déjérine, J. (1914). Sémiologie des affections de système nerveux. Paris: Masson.

Dewarrat, G. M., Annoni, J. M., Fornari, E., Carota, A., Bougousslavsky, J., Maeder, P. (2009). Acute aphasia after right hemisphere stroke. Journal of Neurology, 256(9), 14611467.

Duchan, J. F. (2011). A history of speech-language pathology. Accessed at http://www.acsu.buffalo.edu/ duchan/new_history/early_modern/aphasia_history_before _1800.html (13.12.2015).

Eling, P. (1994a). Introduction. In idem (coord.), Reader in the history of aphasia: From Franz Gall to Norman Geschwind (pp. xi-xvi). Amsterdam: John Benjamins.

Eling, P. (1994b). Introduction. In idem (coord.), Reader in the history of aphasia: From Franz Gall to Norman Geschwind (pp. 35-39). Amsterdam: John Benjamins.

Engelter, S. T., Gostynski, M., Papa, S., Maya, F., Claudia, B., Vladeta, A. G., et al. (2006). Epidemiology of aphasia attributable to first ischemic stroke: Incidence, severity, fluency, etiology, and thrombosis. Stroke, 37, 1379-1384.
Filley, C. M. (2011). Neurobehavioral anatomy (ed. a treia). Boulder, CO: University Press of Colorado.

Finkelnburg, C. M. (1870). Sitzung der Niederrheinischen Gesellschaft in Bonn. Medizinische Section, Berliner Klinische Wochenschrift, 7, 449-450, 460-462.

Finger, S. (1994). Origins of neuroscience: A history of explorations into brain functions. Oxford: Oxford University Press.

Geschwind, N. (1965). Disconnexion syndromes in animals and man. Brain, 88, 237-294, 585-644.

Goldenberg, G. (2013). Apraxia: The cognitive side of motor control. Oxford: Oxford University Press.

Goodglass, H., Kaplan, E. (1972). Assessment of aphasia and related disorders. Philadelphia, PA: Lea \& Febiger.

Head, H. (1915). Hughlings Jackson on aphasia and kindred affections of speech. Brain, 38, 1-190.

Heeschen, C. (1994). Introduction. In P. Eling (coord.), Reader in the history of aphasia: From Franz Gall to Norman Geschwind (pp. 5-15). Amsterdam: John Benjamins.

Hécaen, H., Dubois, J. (1969). La naissance de la neuropsychologie du langage (1825-1865). Paris: Flammarion.

Hier, D. B., Yoon, W. B., Mohr, J. P., Price, T. R., Wolf, P. A. (1994). Gender and aphasia in the Stroke Data Bank. Brain and Language, 47(1), 155-167.

Howard, D., Hatfield, F. (1987). Aphasia therapy: Historical and contemporary issues. Hillsdale, NJ: Lawrence Erlbaum. Hughlings Jackson, J. (1874). On the nature of the duality of the brain. Medical Press and Circular, 1, 19, 41, 63.

Joynt, R. L., Benton, A. L. (1964). The memoir of Marc Dax on aphasia. Neurology, 14, 851-854.

Kean, M.-L. (1994). Introduction. In P. Eling (coord.), Reader in the history of aphasia: From Franz Gall to Norman Geschwind (pp. 355-359). Amsterdam: John Benjamins.

Keyser, A. (1994). Introduction. In P. Eling (coord.), Reader in the history of aphasia: From Franz Gall to Norman Geschwind (pp. 63-68). Amsterdam: John Benjamins.

Lebrun, Y. (1994). Introduction. In P. Eling (coord.), Reader in the history of aphasia: From Franz Gall to Norman Geschwind (pp. 223-229). Amsterdam: John Benjamins.

Luria, A. R. (1962/1966). Higher cortical functions in man. New York: Basic Books / Consultants Bureau.

Luria, A. R. (1964). Factors and forms of aphasia. In A. V. S. De Reuck şi M. O'Connor (coord.), Ciba Foundation Symposium on Disorders of Language (pp. 143-161). Londra: J. \& A. Churchill.

Luria, A. R. (1970). Traumatic aphasia: Its syndromes, psychology and treatment. Haga: Mouton / de Gruyter.

Luzzatti, C. (2002). Johann August Philipp Gesner (17381801). A review of his essay 'The language amnesia' in the bicentennial anniversary of his death. Journal of the History of the Neurosciences, 11(1), 29-34.

Manasco, M. H. (2016). Neurogenic communication disorders (second edition). Burlington, MA: Jones \& Bartlett. 
Marie, P., Foix, C. (1917). Les aphasies de guerre. Revue neurologique, 25, 53-87.

Mesulam, M. (1982). Slowly progressive aphasia without generalized dementia. Annals of Neurology, 11(6), 592-598. Meunier, L. (1911). Histoire de la médicine depuis ses origines jusqu'à nos jours. Paris: Le François.

Naudé, H., Pretorius, E. (2010). Can herpes simplex virus encephalitis cause aphasia? Early Development and Care, 173(6), 669-679.

Ombredane, A. (1926). Sur le mécanisme de l'anarthrie et sur les troubles associés du langage intérieur. Journal de Psychologie Normale et Pathologique, 23, 940-955.

O'Dell, S. E., O'Dell, G. E. (1899). Phrenology: Essays and studies. Londra: The London Phrenological Institution.

Renier, W. O. (1994). Introduction. In P. Eling (coord.), Reader in the history of aphasia: From Franz Gall to Norman Geschwind (pp. 201-204). Amsterdam: John Benjamins.
Schulte, B. P. M. (1994). Introduction. In P. Eling (coord.), Reader in the history of aphasia: From Franz Gall to Norman Geschwind (pp. 137-142). Amsterdam: John Benjamins.

Tesak, J., Code, C. (2008). Milestones in the history of aphasia: Theories and protagonists. Hove, Marea Britanie: Psychology Press.

Trousseau, A. (1864). De l'aphasie, maladie décrite récemment sous le nom impropre d'aphémie. Gazette des hôpitaux civils et militaires, 37, 13-14, 25-26, 37-39, 48-50. Trousseau, A. (1868). Clinique médicale de l'Hôtel-Dieu de Paris (third edition, vol. 2). Paris: Baillière et Fils.

Wernicke, C. (1874). Der aphasische Symptomenkomplex. Eine psychologische Studie auf anatomischer Basis. Breslau: Cohn \& Weigert.

Wernicke, C. (1886). Einige neuere Arbeiten über Aphasie. Fortschritte der Medizin, 4, 371-377, 463-469.

Whitaker, H., Etlinger, S. (1993). Theodor Meynert's contribution to classical 19th century aphasia studies. Brain and Language, 45, 560-571. 